\title{
Visual figural after-effects and field dependence
}

\author{
LUDWIG IMMERGLUCK ${ }^{1}$ \\ SAN FRANCISCO STATE COLLEGE
}

Visual figural after-effects are shown to be related to measures of field dependence (as assessed by the Rod and Frame Test). Field independent $S$ s exhibited such after-effects while field dependent $S_{s}$ failed to demonstrate these effects on a specific perceptual task. Since measures of field dependence have been previously found to relate to broader personality and behavior variables, the present evidence suggests then that such complex behavior variables might in turn be related to elemental cortical traces of a type involved in the generation of figural after-effects.

Although Gibson's (1933) first systematic accounts of figural after-effects generated increasing research interest in this aspect of the perceptual process, up to date, the pertinent literature makes only very scant reference to the presence of individual differences. To be sure, Wertheimer (1954) reports that schizophrenics show weaker after-effects than do normal Ss, while Eysenck (1955), utilizing kinesthetic after-effects, demonstrates more pronounced after-effects in hysterics. However, no concerted attempts have as yet been made to relate systematically individual differences found within normal $\mathrm{S}$ groups to specific and circumscribed variables, though an often wide range of such individual differences are seen in the results of a great many studies. Ss, for example, under identical test conditions differ not only with regard to the magnitude of the elicited after-effect or the speed of its decay, but there are some in whom after-effects are evoked only with great difficulty or else those who appear to show no such effects at all. Are these differences systematically related to other perceptual response categories, to more complex behavior variables, and finally to some presumed differences in cortical activity which is directly concerned with the absorption and trace perseverance of elemental and externally originated stimuli?

The present experimental investigation seeks to relate individual differences on a visual figural after-effect task to another perceptual response category, namely, field dependence. The relevance of this relationship may best become apparent when one understands that the basic operanda involved in perceptual measures of field dependence-field independence pertain essentially to a S's immediate and momentary relationship to a present stimulus field. Thus, "field independent" Ss can divorce themselves, so to speak, from the pushing and pulling forces of the immediate stimulus situation, while "field-dependent" Ss are more directly, concretely, and presumably passively bound to external stimuli and cannot transcend their particular pulls.
In the well known Rod and Frame Test, first used extensively by Witkin (1954) and his associates, the S is presented in an otherwise totally dark room with a tilted luminous bar surrounded by a luminous square frame which can be tilted, independent of the bar, by the examiner at various angles, and he is required to adjust the bar to its true vertical position while disregarding the various tilts of the frame. Typically, "field-independent" Ss are able to disregard the tilt of the surrounding frame and, drawing on some inner cues-such as perhaps their own body position-can establish the vertical position of the bar with relatively great accuracy, while "field-dependent" Ss, swayed by the tilt of the frame, make grossly inaccurate judgments regarding the true vertical position of the rod.

Since figural after-effects, and more specifically that aspect pertaining to the perception of the test figure following the fixation of the original inspection stimulus, also involve a S's relationship to an immediately present stimulus field, it is hypothesized that "field-dependent" Ss, being more affected by the attributes of an immediately present stimulus, should show weaker figural after-effects. And conversely, for "field-independent" Ss, i.e., Ss who are less tied to an "outer" and immediately present stimulus field, an "inner" cortical trace should be more potent, with the consequent occurrence of greater after-effect phenomena.

\section{Method}

The $S$ groups, college students ranging in age from 19 to 23 years, were selected on the basis of their performance on the above described Rod and Frame Test. Only those Ss were chosen who had extreme scores in either the direction of field independence or field dependence. A consistent deviation from the true vertical of $10^{\circ}$ or more constituted the field dependent group while those subjects who were able to locate the rod consistently within $3^{\circ}$ of its true vertical position were placed in the field independent subject group. By this method the final $S$ groups of 27 field independent and 19 field dependent were established.

All Ss were then exposed to a figural after-effect test illustrated in Fig. 1. This is a slightly modified version from similar geometric designs employed extensively in previous investigations and demonstrations of after-effects. The 1 Figure consists of two different sized squares, one measuring 1 in., the other 1.5 in., separated equally by $2 \mathrm{in}$. from their respective centers to the central fixation point. After a fixation time of 30 sec., the T Figure, consisting of two identical squares 1.5 in., was immediately presented to the S. The Ss were then asked to identify the test squares as "equal." or "unequal." Presence of the after-effect is demonstrated by a S's perception of the test squares as "unequal."2

\section{Results and Discussion}

Table 1 contrasts the Test Figure judgments for both the field independent and the field dependent $S$ groups. The test data indicate clearly the presence of a signi- 

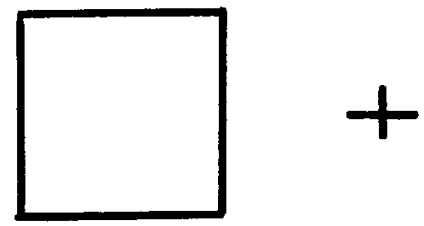

I FIGURB
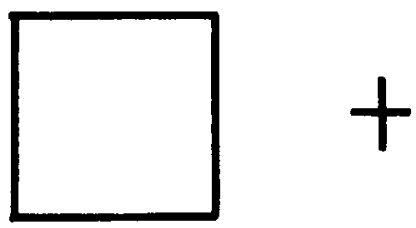

T FIGURE

Fig. 1. The Ss are required to focus the central fixation point (+) of the I Figure for $30 \mathrm{sec}$, after which the $T$ Figure is immediately presented for perceptual judgment. The left-hand square of the $I$ Figure is identical with both squares of the $T$ Figure (1.5 in.) while the right-hand I Figure square is smaller ( 1 in.). When the after-ffect is operative, the right-hand $T$ Figure square (presented in the same visual area as the previously fixated smaller square) is typically perceived as larger in comparison to the left-hand square.

ficant difference $(p<0.01)$ in the perception of the test figures between the two $\mathrm{S}$ groups. As a group, the field independent $\mathrm{Ss}$ perceived the objectively equal test squares as unequal, while the dependent Ss did not report any size differences.

At this point it might be well to note that Witkin and his associates, who originally formulated the concepts of field dependence and field independence as used in this experiment go beyond the Ss' experimentally observed perceptual behavior, and relate these perceptual styles to broader behavior and personality variables. They offer evidence, for example, that field de-

Table 1. Figural After-effects

$\begin{array}{lrr} & + & - \\ \text { Field Independent Subjects } & 20 & 7 \\ \text { Field Dependent Subjects } & 7 & 12\end{array}$

The (+) column indicates the number of Ss showing figural after-effects and the (-) column those who did not demonstrate the effect. The difference between the groups is significant $\left(X^{2}=6.14\right.$ and $\left.p<0.01\right)$. pendent Ss, as measured by perceptual tasks, are also behaviorally dependent, passive, compliant, and typically insecure individuals, while perceptually independent Ss show a greater measure of independence in their personality functioning and are as a group more flexible, less group conforming, and creatively independent.

While the central aim of the present study is to demonstrate a relationship between two perceptual response categories, figural after-effects on the one hand, and a specific measure of field dependence on the other, and does not purport to assess directly broader personality or behavioral variables, the present data demonstrate, nonetheless, significantly different effects produced by simple visual stimuli upon cortical functioning for "field-independent" and "field-dependent" $S$ groups: in the former, the stimulus leaves a cortical trace which has a telling effect upon the S's subsequent intercourse with new stimuli, while in the latter such effects are not demonstrated, and whatever cortical impact a continuously fixated stimulus may have, its subsequent trace is apparently obliterated by the impact of new and immediately present stimulus forces. The present data suggest that different neurophysiological processes exist, as far as the cortical absorption of a visual stimulus is concerned, for field dependent and field independent Ss. Should future research show that the magnitude of stimulus after-effects is systematically relatable to complex behavioral and personality variables, then we must also conclude that such broad behavior patterns might be in turn related to some elemental cortical process such as is exemplified by the impact of a single external stimulus and the relative strength of its subsequent trace.

\section{References}

Eysenck, H. J. Cortical inhibition, figural after-effect and the theory of personality. J. abnorm. soc. Psychol, 1955, 51, 94106.

Gibson, J. J. Adaptation, after-effect and contrast in the perception of curved lines. J. exp. Psychol., 1933, 16, 1-31.

Wertheimer, M. The differential satiability of schizophrenic and and normal subjects: a test of the deduction from the theory of figural after-effects. J. gen. Psychol., 1954, 51, 291-9.

Witkin, H. A., Lewis, H. B., Hertzman, M., Machover, K., Meissner, P. B., \& Wapner, S. Personality through perception. New York: Harper, 1954.

\section{Notes}

1. This study was supported by a faculty research fund, San Francisco State College, under the auspices of a National Science Foundation Institutional Grant.

2. In order to ascertain more unequivocally whether an aftereffect had indeed been obtained, all subjects who perceived the $T$ Figures as being "unequal" were required to specify this response. All these subjects identified "unequal" as meaning that the right-hand T Figure was "larger." 